\title{
Factors associated with the life satisfaction amongst the rural elderly in Odisha, India
}

\author{
Pallavi Banjare,, Rinshu Dwivedi and Jalandhar Pradhan
}

\begin{abstract}
Background: Life Satisfaction (LS) is an indicator of subjective well-being (SWB) among the elderly, and is directly associated with health and mortality. Present study deals with the factors associated with the LS among the rural elderly in Odisha, India.

Methods: A cross-sectional survey using multi-stage random sampling procedure was conducted among elderly (60+ years) in Bargarh district of Odisha. The survey was conducted among 310 respondents. Hierarchical regression analysis was used to assess the adjusted effect of various socio-economic, demographic, health conditions (physical and mental), social support and effects of multi-morbidity on LS.

Results: Cognitive health was the most influential factor in determining $L S$ among both men $(\beta=0.327)$ and women ( $\beta=0.329$ ). Individual's social support also plays an influential role in LS among rural elderly. Elderly who are living alone and have any sort of disability and had low score of activities of daily living (ADL) have also reported significantly lower perceived LS for both the genders.

Conclusion: It is necessary to analyze and identify the major factors which can improve upon the level of LS among the elderly population. Better understanding of these factors can help in removing the superfluous anxiety of old age in the mindset of people which is pervading in the society.
\end{abstract}

Keywords: Elderly, Life satisfaction, Morbidity, Social support, Cognitive health

\section{Background}

Life satisfaction (LS) is an important component of successful aging. Successful aging is a universal phenomenon, which is not uniform across the different age groups, and it differs from person to person. Some accomplish a sense of fulfillment and satisfaction in old age, while others turn harsh and hostile to the changes of old age and lament on the decline of their physical activities [1,2]. Level of LS indicates the subjective wellbeing which is associated with the health and mortality status among the elderly. It is among the one of the main determinants of well-being, which reflects the cognitive judgmental aspect of an individual [3]. Older people who experienced bad health tend to express low level of LS. However having higher socioeconomic status, adequate family support, higher level of satisfaction with one's living environment/condition, and

\footnotetext{
* Correspondence: pallavibanjare@gmail.com

Department of Humanities and Social Sciences, National Institute of Technology, Rourkela 769 008Orissa, India

staying in their own home among the elderly population plays a crucial role in achieving successful aging $[4,5]$.

LS refer to a judgmental process, in which individual access their quality of life (QoL) in accordance with some unique set of criteria's. Elderly are more sensitive to their LS and health conditions, which is further influenced by their socioeconomic situations, and limited work performance [6, 7].

As per the WHO, four factors which directly influences the level of LS among the elderly are: physical health condition, mental health condition, social relationship and environment [8]. For improving LS among the elderly, it is necessary to consider factors like satisfaction in residential environment, neighborhood relationship, economic status, maintaining friendship, family relationship, physical health condition, satisfaction in marital status, job or career, and lastly, satisfaction in others aspect of life [9].

LS is influenced by various factors like demographic, socio-economic, health, physical status, mental status, 
social support, social adjustment and number of morbidities. Studies indicate that factors such as race, socioeconomic status, marital status, education, level of selfesteem, depression, may influence the level of LS. In terms of demographic factors, increase in age has a significant impact on the LS among females in comparison to males [10]. Few studies have recorded that neither age nor gender was positively associated to LS $[11,12]$. Time-varying physical health is related to changes in LS [13]. Change in marital status is related to the LS path, and new widowhood is related to morale and social engagement. Women and men in formal marriages experience higher levels of LS than people in other forms of marriages $[14,15]$.

There is a moderate effect of socioeconomic status, including income and educational level, on LS [16-19]. A study on LS amongst elderly people living in Australia, found that social, health, security of life, residence, acceptance and adjustment influences the level of LS among the elderly [20]. Studies also showed that residential status have a negligible impact on LS [21].

Most of the research was focused on activities of daily living (ADLs) and instrumental activities of daily living (IADLs) as an indicators to evaluate the health condition of elderly and LS. Physical activities, viz. bathing, dressing, toileting, continence, movement and food intake including ADL, are positively related to LS [22, 23]. However, few studies show that physical disability was not significantly related to LS [24]. As per a study among 132 countries, by Gallup organization, there are stronger evidences that health and LS among the elderly people decreases with increase in the level of disability and age. This study also indicates towards differences among the developed and developing countries as decline in LS with disability and age was more among the developing and underdeveloped nations [25].

There is a positive relationship between psychological well-being and LS. Psychological health is generally related to overall subjective well-being, and there is a significant relationship between depressive symptoms and LS [26, 27]. Psychosocial variables like size of social support, social support and positive social relations are strongly related to LS $[28,29]$. There is a significant effect of physical and psychological well-being on LS while, socio-demographic variables such as gender or age plays very limited role in LS [30, 31].

Social support systems like religion, education, marriage, occupation, active daily life status, living arrangement, diet, transportation, family support and emotional support also have a positive impacts on the LS of elderly $[32,33]$. If the income of the households is lower in that case family support has a greater effect on happiness among elderly while emotional support has been found to work as a shield during traumatic periods and increases LS [34]. In few communities, relationships with friends are more important for the LS among elderly population [35]. Continuous working and participation in volunteering activities or community events are also related to the higher level of subjective well-being [36].

Various studies indicate social support as a factor which has a strong influence on the LS among the elderly. Literature suggests that psychological variable and locus of control affects subjective well-being more than social support and LS in elderly individuals [37]. Factors like household environment (both physical and social), overall well-being, personal information (information on age, sex, education and place of residence), self-acceptance (social support), personal traits (cognitive health) and lifestyle indicators (smoking, consuming tobacco and alcohol) are correlated with the LS among the elderly population [38, 39].

Studies also explored the factors associated with the LS which have been experienced during the process of aging. In case of within the group distribution of elderly population (health inequity) ${ }^{1}$, results indicates that economic position and health were the most important factors determining levels of LS among elderly individuals [40]. LS is a forecaster of longevity and morbidity, disease and injury [24]. In addition, LS is also related to other health variables such as favorable self-reported health, social support, and positive health behaviours. Limited evidences are available on the relationship between LS, health behaviours, chronic health conditions, and health-related quality of life (HRQOL) among the elderly. Behavioural Risk Factor (smoking, consumption of alcohol and tobacco) chronic illness and adverse health behaviours are correlated with HRQOL and influences LS [41-43].

In Indian context, Maheswaran and Ranjit [44] focused on LS and influence of demographic factors on LS of the elderly people. Results indicate that majority of the respondents had low level of LS. Moreover, the demographic factors namely gender and habit of savings directly influences the level of LS of the elderly respondents. The variables viz. health problems, ownership of house, ownership of land, religion, monthly income and number of children, negligibly influence the level of LS.

Balachandran et al. [45] studied LS and alienation of elderly males and females in the district of Kerala, India. The results indicate that elderly men experience less alienation in comparison to the elderly women. However, both elderly male and females do not exhibit significant differences in their LS. Marpady et al. [46] conducted a study in rural Karnataka, India to explore the pattern of social support system and LS amongst the elders. The research revealed that family support is a significant factor for the better psychological wellbeing of the elderly. It was also observed that homebound elderly had more advantages than the institutionalized elderly in 
terms of daily activities, level of satisfaction, social support and source of financial support.

India is the second most populated country in the world, with nearly 100 million persons aged above 60 years, which constitutes about $8.3 \%$ share in the total population [47]. As the elderly population is on a rise throughout the globe specifically in India, various aspects of ageing and its precursors have become an area of research for gerontologists and social scientist.

After reviewing the literature from international as well as in Indian context, major gaps has been identified. Limited number of studies has highlighted the role of either demographic, socio-economic, social support or cognitive health. As per our information there are no such studies which have completely addressed the issue of LS among the rural elderly by taking into consideration all major variables which influences the level of LS. Present study is an attempt to fill this existing gap in the literature and provides a linkage between all the major factors such as demographic, socio-economic, social support and cognitive health variables. This paper examines the relationship between various covariates of LS among the rural elderly in Bargarh district of Odisha on the basis of following hypothesis:

H1: Elderly having better cognitive health are having better LS.

H2: Elderly having good social support are having better LS.

H3: Elderly having no morbidities are having better LS.

This paper aims to analysis the factors constructing LS amongst the rural elderly of Odisha and explores its implications on their health and life, which can positively contribute in developing social policies.

\section{Methods}

\section{Ethics statement}

The study was conducted in Bargarh district of Odisha, India. The study aims to explore the familial setups, roles, health status and expectations of the elderly. Before collecting necessary information from selected elderly, following consent form was signed by the respective respondent:

"I am going to ask you some personal questions that some of the people find difficult to answer. Your answers are completely confidential, your name, will not be disclosed to anyone, and will never be used in connection with any of the information you tell me. You do not have to answer any questions that you do not feel comfortable, and you may withdraw from this interview at any time you want to. However, your answers to these questions will help us to understand the senior citizens situation. We would greatly appreciate your help in responding to this interview. Would you be willing to participate?"

If the respondent provided consent, an interview was conducted.

The study was approved by the Doctoral Research Committee (DRC) of National Institute of Technology, Rourkela, Odisha, India.

\section{Study area and subjects}

A cross-sectional survey using multi-stage random sampling procedure was conducted among elderly (60+ years) in Bargarh District of Odisha (Fig. 1). The targeted sample size of the population was 320. Data were collected by face-to-face interviews with a pre-tested structured questionnaire. Ten respondents who were extremely frail could not respond to the questionnaires. So, finally 310 respondents were considered for analysis resulting in a response rate of $97 \%$. In order to increase the efficiency of estimates, a multistage sampling design was followed to select required number of respondents for interview. Selection of respondents involved three stages of sampling procedure. Block ${ }^{2}$ was selected at the first stage. Then village ${ }^{3}$ was selected at the second stage followed by selection of target respondents at the third stage.

As per Census 2001, there are 12 blocks in Bargarh i.e. Bargarh, Barpali, Attabira, Bheden, Sohella, Bijepur, Padmpur, Gaisilet, Paikmal, Jharbandh, Ambabhona and Bhatli. Two blocks namely Sohella and Padampur were selected randomly. Twenty respondents (10 Male and 10 Female) were selected from each village. So, 16 villages ( 8 from Sohela and 8 from Padampur) were selected to get the required number of respondents. Villages were selected using probability proportion to sample size (PPS). At the village level, a sampling framework was prepared separately for male and female respondents. A complete listing of the households in a selected village was done. During the listing in each household all the members aged $60+$ were listed. Each member's actual age and gender were noted. Accordingly, 10 Male and 10 Female elderly were selected by using systematic random sampling procedure. The study was conducted in Bargarh district as the percentage of elderly population was higher than the state average and ratio of female elderly population was also higher in the district than the male elderly population [47].

\section{Framework of the study}

In order to investigate various factors associated with LS among elderly we have partially derived the framework of the study from Coke and Twaite [48] and Neugarten et al. [49]. As per Life Satisfaction Index (LSI), successful ageing depends upon the general feelings of well-being 


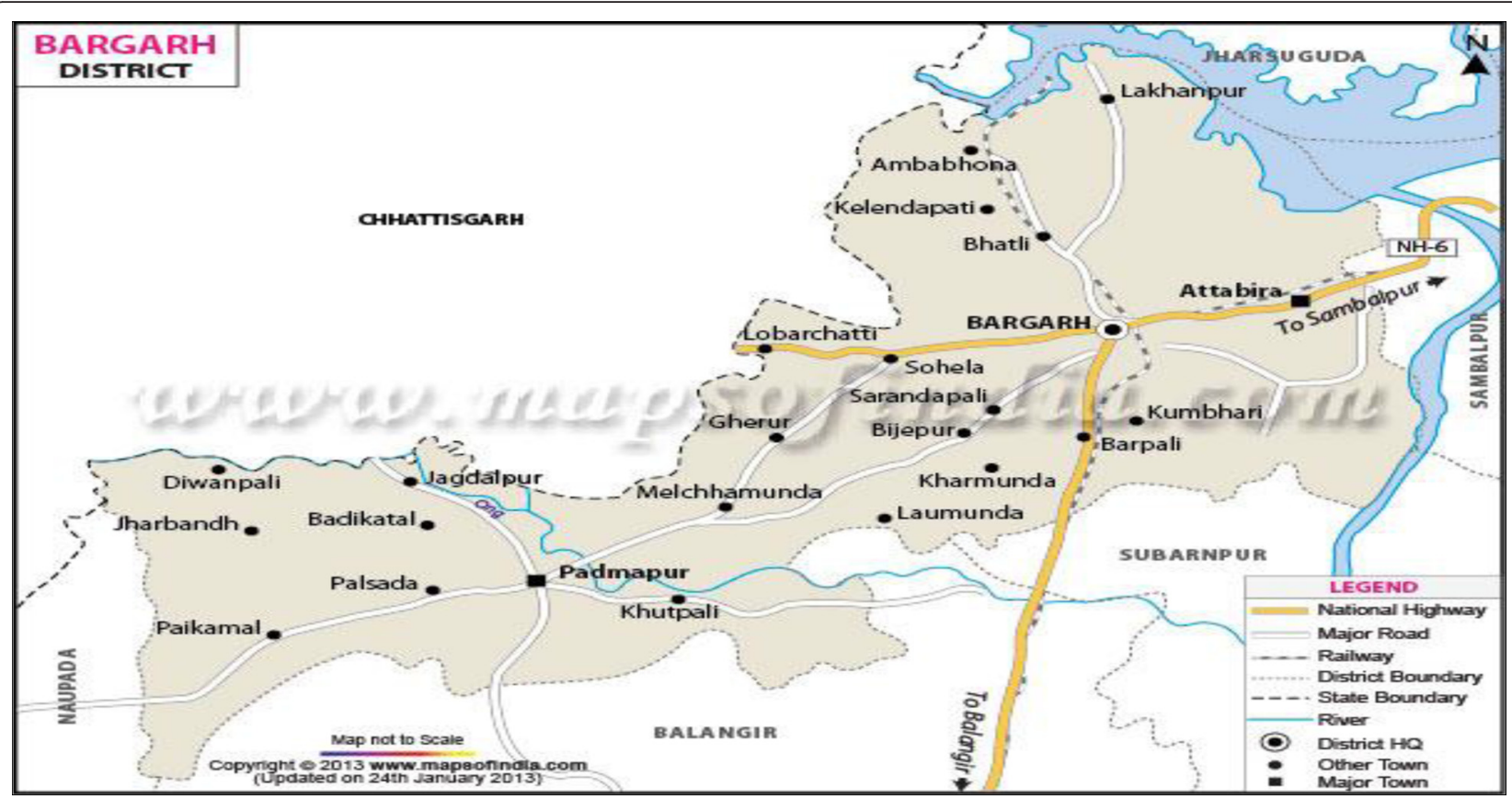

Fig. 1 Map of Bargarh district in Odisha

among older people and positively contributes into the LS. The concept of LS is associated with various factors like demographic variable, socio-economic factors, health behavior, physical health status, cognitive health status, social support and number of morbidities among elderly. We have recorded responses on these above mention aspects by asking questions through a structured questionnaire from the respondents. The framework of the study is summarized in Fig. 2.

\section{Katz Index of independence in ADL}

As aging process sets in it results into the changes in the health status of the individual and decline in the functional status of older adults. The most appropriate method or tool to access ADL of the elderly is the Katz Index of Independence in ADL, commonly referred to as the Katz ADL. It was developed by a medical doctor Sidney Katz In 1969 [50]. The Index ranks adequacy of performance in the six functions of bathing, dressing, toileting, transferring, continence, and feeding. Clients are scored yes/no for independence in each of the six functions. A score of 6 indicates full function, 4 indicate moderate impairment, and 2 or less indicates severe functional impairment.

\section{Variables under study}

Variables used for the study (both dependent and independent) has been explained below.
Dependent variables: We have taken LS as our dependent variable. In order to determine LS, respondents were asked, "Taking all things together, how would you say you are these days"? The responses were on Likert scale ranging from (1.very happy, 2.happy, 3. neither happy nor unhappy, 4. unhappy and 5 . very unhappy.

Independent variables: The independent variables are; a) Age (reference group: 65+ years), b) Marital status (reference group: Not currently married), c) Caste ${ }^{4}$ (reference group: SC/ST/ general), d) Education (Likert scale) e) Wealth quintile (Likert scale), f) state of economic independence (reference group: dependent), g) living arrangements (reference group :living alone),

h) Risk behaviour (reference group: consuming tobacco, smoking, and drinking alcohol i) disability status (reference group: not disabled), j) Functionality or ADL (reference group: functional), (k) cognitive health status (reference group: bad cognitive health, l) social supports (reference group: not having good social supports), m) morbidity status (reference group: no morbidity). We tested multi-co linearity for all independent variables, and in no case was the tolerance value less than 0.1 or the variance inflation factor (IVF) greater than 10 (Table 1).

\section{Statistical analysis}

Statistical analysis was carried out in two stages: firstly; the sample characteristics of the elderly population was assessed for each variable using descriptive statistics by 


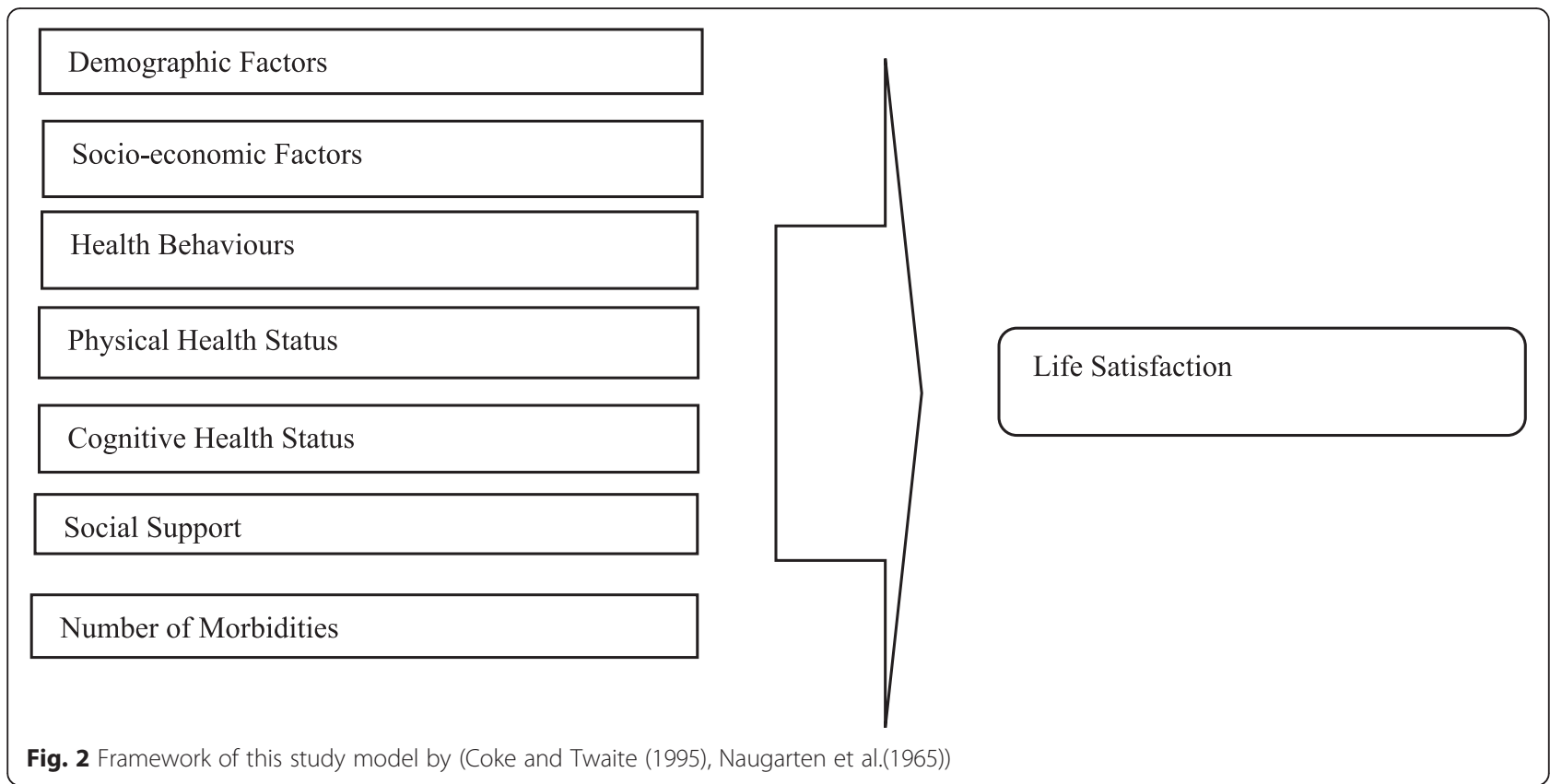

also focusing upon the observation of elderly population with chronic diseases. Later on, hierarchal multiple regression analysis was used as per Gender. Hierarchal regression by gender was employed as per the available literature which shows that gender has a significant effect on LS among elderly. Literature on differences in pain experiences indicates towards gender variations, where women generally experience more experimental pain in comparison to men. Moreover the perception, attitude and approach towards life are very different among both the genders. Level of LS is lower among those men who are living alone or without their spouse while among females, LS is lower when they used to stay with their relatives or their parents-in-law. Similarly residing with an unmarried son is negatively associated with LS for both genders [51]. Women LS increases with higher number of social activities and friend circle which is not that significant predictor of LS among the males [52]. Overall family relations are of more importance to males in comparison to females. Elderly men whose

Table 1 Variables used in the study

\begin{tabular}{|c|c|c|}
\hline Predictive variables & Parameters & Instruments \\
\hline \multirow[t]{4}{*}{ Health Behaviours } & Question : Do you have any of the following habits & $\begin{array}{l}\text { Questionnaire containing dichotomous responses } \\
\text { (Yes/No) }\end{array}$ \\
\hline & a) Smoking & \\
\hline & b) Consumption of alcohol & \\
\hline & c) Consuming tobacco & \\
\hline Social networks & $\begin{array}{l}\text { Question: Do you have keep in touch with your relatives or } \\
\text { friends? }\end{array}$ & $\begin{array}{l}\text { Questionnaire containing dichotomous responses } \\
\text { (Yes/No) }\end{array}$ \\
\hline \multirow[t]{4}{*}{ Morbidity } & No Morbidity & International Classification of Diseases (ICD)-10 \\
\hline & At least one morbidity & \\
\hline & At least two morbidity & \\
\hline & Three or more morbidity & \\
\hline \multicolumn{3}{|l|}{ Disability } \\
\hline Physical disability & Vision, hearing, walking, chewing, speech, memory. & $\begin{array}{l}\text { Questionnaire containing dichotomous responses } \\
\text { (Yes/No) }\end{array}$ \\
\hline $\begin{array}{l}\text { Activities of Daly Living } \\
(A D L)\end{array}$ & Feeding, continence, transferring, toileting, dressing, bathing. & Katz scale \\
\hline Psychological distress & $\begin{array}{l}12 \text { questions related with psychological wellbeing among } \\
\text { elderly }\end{array}$ & General Health Questionnaire (GHQ)-12 \\
\hline
\end{tabular}


marital status remained stable there LS was also constant while in case of females there was a decline in LS. In addition, among males LS increases with marriage while it has no significant role for females [53]. Data analysis was done using SPSS 20 software.

\section{Results}

The sample characteristics of the studied population by selected socio-economic covariates shows that out of the total sample of 310 respondents, 153 are male and 157 are female (Table 2). The married people comprise of $60.3 \%$ and widowed / divorced or separated comprise of $39.7 \%$ of the total sample. Study on Literacy or Education of the respondent's shows that about $60.3 \%$ have no formal education, followed by $27.7 \%$ who have completed primary education or less and only $4.5 \%$ have completed their secondary school and above. In State of Economic Dependence, about $46.5 \%$ are partially dependent, followed by not dependent on others and $11.3 \%$ are fully dependent on their spouse, son or other relative. While analyzing caste structure, Other Backward Caste $(\mathrm{OBC})$ have the highest share of $57.1 \%$, followed by Scheduled Caste (SC)/ Scheduled Tribe (ST) with $31.9 \%$ and general have $11 \%$ only. Elderly living with spouse and married son are about $54.5 \%$, followed by living with either spouse/son or daughter and elderly living alone are the least with only $7.7 \%$ share. Predominantly, in the to the Indian system of old-age support and living arrangement there is the norm that sons support their parents; that is, they provide financial and practical support for their elderly parents. Elderly parents mostly live with their elder son and daughters are treated as outsiders after their marriage [54] Staying with a married daughter is still regarded as a taboo in rural settings in India. Those elderly who don't have any son stay either alone or with some relative and daughters often visit them and provide them with some financial support [55].

As this study was also done in the rural setup the percentage of elderly living with the married daughter was negligible so it was not taken into account. About $58.1 \%$ of the population have Below Poverty Line (BPL) card. About $63 \%$ of the respondents are consuming tobacco, $31 \%$ of them are used to smoking and a small proportion (4\%) in drinking alcohol. Nearly $63 \%$ of the elderly are having good social support. Majority of the elderly were not disabled (70 \%) as only $30 \%$ of them were having some sort of disability. Half of the elderly population was having poor cognitive health status and only $14 \%$ of the elderly were having good cognitive health status. About $77 \%$ of the elderly population in the district was in functional state and $23 \%$ have some issues with ADL.
While comparing the prevalence of disease amongst males and females, it shows that arthritis is more common among females than males, whereas Chronic Obstructive Pulmonary Disease (COPD) and high blood pressure are more common among males. Similarly, dementia and Alzheimer's disease are more common among females and cataract amongst males. For other diseases, both male and females shared similar patterns with few variations (Table 3 ).

The normal P-P plot of regression standardized residual and scatter plot, indicates the outliers, normality, linearity and homoscedasticity. The purpose of P-P plots is to check if the data are normally distributed so here the data are plotted against a theoretical normal distribution in such a way that the points should form an approximate straight line. Departures from this straight line indicate departures from normality. Here the normal P-P plot points are lying in the straight diagonal line from the bottom left to top right showing normal distribution of data and fit for analysis. In scatter plot, residuals are rectangularlly distributed with most the scores concentrated at the center i.e. along the point O. Standardized residuals of more than 3.3 or less than -3.3 indicates outliers (Figs. 3 and 4) [56].

The model summary of both dependent and independent variables shows $R^{2}$ value and variables entered in Block one (age, caste, marital status, education, wealth index, state of economic dependence, living arrangements, life style indicators, ADL, cognitive health and social adjustment,). They together explain $30 \%$ of the variance $(.30 * 100)$ in dependent variable (DV). After entering the variable gender in block two the model now explains $35 \%$ of variance in the DV. The $R^{2}$ change in model two here again explains an additional of $5 \%$ variance in DV by variable gender. This is a significant contribution, as indicated by sig $F$ change value for this line (0.000) (Table 4).

Present method is suitable for this study as in this method the effects and coefficient values of each factor on the level of LS and incremental change (increase/decrease) in the $R^{2}$ value are provided in comparable forms. All the five models are considered for the analysis and variables are added in each model and the final model contains all the 13 variables used in the analysis (Table 5). We have conducted a hierarchical regression analysis with respect to gender in order to identify the main covariates which determine the level of LS in elderly population (Tables 6 and 7). Five sets of models were introduced and the result of final model is presented after the introduction of 13 variables. Results shows that 6 variables were statistically significant for both men (adj. $\left.R^{2}=0.384\right)$ and women (adj. $R^{2}=0.386$ ).

The most important factor that was influencing LS for both males and females are: individual's cognitive health, $(\beta$ 
Table 2 Percent distributions of sampled population by selected socio-economic co-variates, health conditions and risk behaviour

\begin{tabular}{|c|c|c|c|c|c|}
\hline Covariates & Percent & Number & Consuming Alcohol (Yes) & 4.19 & 13 \\
\hline Sex & & & Consuming Tobacco (Yes) & 63.2 & 196 \\
\hline Male & 49.4 & 153 & Disability & & \\
\hline Female & 50.6 & 157 & Disabled & 29.4 & 91 \\
\hline Age of the respondents & & & Not Disabled & 70.6 & 219 \\
\hline $60-65$ Years & 30.6 & 95 & Social support & & \\
\hline $65-70$ Years & 35.5 & 110 & Yes, keep in touch with relatives & 63.2 & 196 \\
\hline 70-75 Years & 20.0 & 62 & No, Don't keep in touch with relatives & 36.8 & 144 \\
\hline 75 \& Above & 13.9 & 43 & Cognitive health & & \\
\hline Marital Status & & & Poor & 49.7 & 154 \\
\hline Currently married & 60.3 & 187 & Average & 36.1 & 112 \\
\hline Widowed/Divorced or Separated/Never married & 39.7 & 123 & Good & 14.2 & 44 \\
\hline Education status of respondents & & & Functionally or Activities of daily living (ADL) & & \\
\hline No formal education & 60.3 & 187 & Functional & 76.8 & 238 \\
\hline Less than primary & 27.7 & 86 & Not functional & 23.2 & 72 \\
\hline Primary school completed & 7.4 & 23 & $\mathrm{~N}$ & 100 & 310 \\
\hline
\end{tabular}

Wealth quintile

Poorest

$19.7 \quad 61$

Poorer

Middle

Richer

Richest

Caste

General

Scheduled Caste/Scheduled Tribe

Other Backward Caste

State of economic dependence

Not dependent

Fully dependent

Partially dependent

Living arrangements

Living alone

Living with spouse/Son/Daughter

Living with Spouse and unmarried son

Living with Spouse and married son

Morbidities

No morbidity

Having one morbidity

Having two morbidity

Having three or more morbidities

Risk Behaviours

Smoking (Yes)
Table 2 Percent distributions of sampled population by selected socio-economic co-variates, health conditions and risk behaviour (Continued)

value; $M=0.327, F=0.329$ ); social support ( $\beta$ value; $M=$ $0.286, \mathrm{~F}=0.284)$; living arrangements $(\beta$ value; $\mathrm{M}=0.179$, $\mathrm{F}=0.178)$; disability ( $\beta$ value; $\mathrm{M}=-0.479, \mathrm{~F}=-0.476$; ADL or functionality ( $\beta$ value; $M=-0.286, F=-0.284$ ) and, morbidity status ( $\beta$ value; $M=-0.077, F=-0.074$ ). The observed differences in the results among men and women can be summarized as follows:

In model $\mathrm{V}$ there has been highest increase in the explanatory power of the $R^{2}$ value in terms of LS for both men and women. We have further added variable like disability, cognitive health and number of morbidities in model $\mathrm{V}$ due to the explanatory power of $R^{2}$ was measured at 0.140 in both male and female. Second highest increase in the explanatory power of $R^{2}$ was observed in model IV where the change in adjusted $R^{2}$ value increased to 0.089 in men and 0.087 in women. In this model, the variables introduced were ADL and social support.

\section{Discussion}

Disability has a significant effect on the LS of elderly people. It is also observed that negative life events may increase psychological distress among elderly people and in turn can lower the level of LS. However there is a direct relationship between social supports and LS, as social support increases LS also increases. Furthermore, disability, preceding psychological distress, lack of friend circle or social support system that could help elderly, low ADL and IADL scores was associated with dissatisfaction with life or lower level of LS $[57,58]$. 
Table 3 Percent of respondents having selected morbidities by Gender

\begin{tabular}{|c|c|c|c|}
\hline Morbidities & Male $(N=153)$ & Female $(N=157)$ & Total (310) \\
\hline Arthritis & 50.9 & 54.7 & 52.9 \\
\hline Cerebral-embolism, stroke or Thrombosis & 0.6 & 1.9 & 1.2 \\
\hline Heart disease & 0.6 & 4.4 & 2.5 \\
\hline Diabetes & 7.8 & 10.8 & 9.3 \\
\hline Chronic obstructive pulmonary disease & 30.0 & 10.1 & 20.0 \\
\hline Asthma & 9.1 & 10.1 & 9.6 \\
\hline Depression & 7.1 & 4.4 & 5.8 \\
\hline High blood pressure & 26.1 & 12.7 & 19.3 \\
\hline Alzheimer's disease & 3.9 & 9.5 & 6.6 \\
\hline Cancer & 0.0 & 1.9 & 0.9 \\
\hline Dementia & 4.5 & 7.6 & 6.1 \\
\hline Liver or gall bladder illness & 4.5 & 3.1 & 3.8 \\
\hline Osteoporosis & 1.9 & 3.1 & 2.5 \\
\hline Renal or Urinary tract infection & 9.1 & 3.8 & 6.4 \\
\hline Cataract & 21.5 & 15.9 & 18.7 \\
\hline Loss of all natural teeth's & 4.5 & 7.0 & 5.8 \\
\hline Accidental injury (in past one year) & 11.7 & 6.3 & 9.0 \\
\hline Injury due to fall (in past one year) & 3.9 & 2.5 & 3.2 \\
\hline Skin disease & 6.5 & 7.0 & 6.6 \\
\hline Paralysis & 8.4 & 4.4 & 6.4 \\
\hline
\end{tabular}

LS and mental health are associated with some specific demographic factors such as age and gender. In addition, self-rated health and limited functionality due to disability exert a significant impact on psychological well-being and can lead to depressive symptoms, and psychological distress. The relationship between ADL, psychological factors and LS was different between males and females.
It is a well-established fact that with increasing age, there are higher likelihood of morbidity and disability. This may be due to the nature or occurrence of disease as older people do not encounter with fatal diseases rather they suffer from chronic diseases [59, 60].

The LS of the elderly population relies on factors such as living arrangement, health condition, economic status,

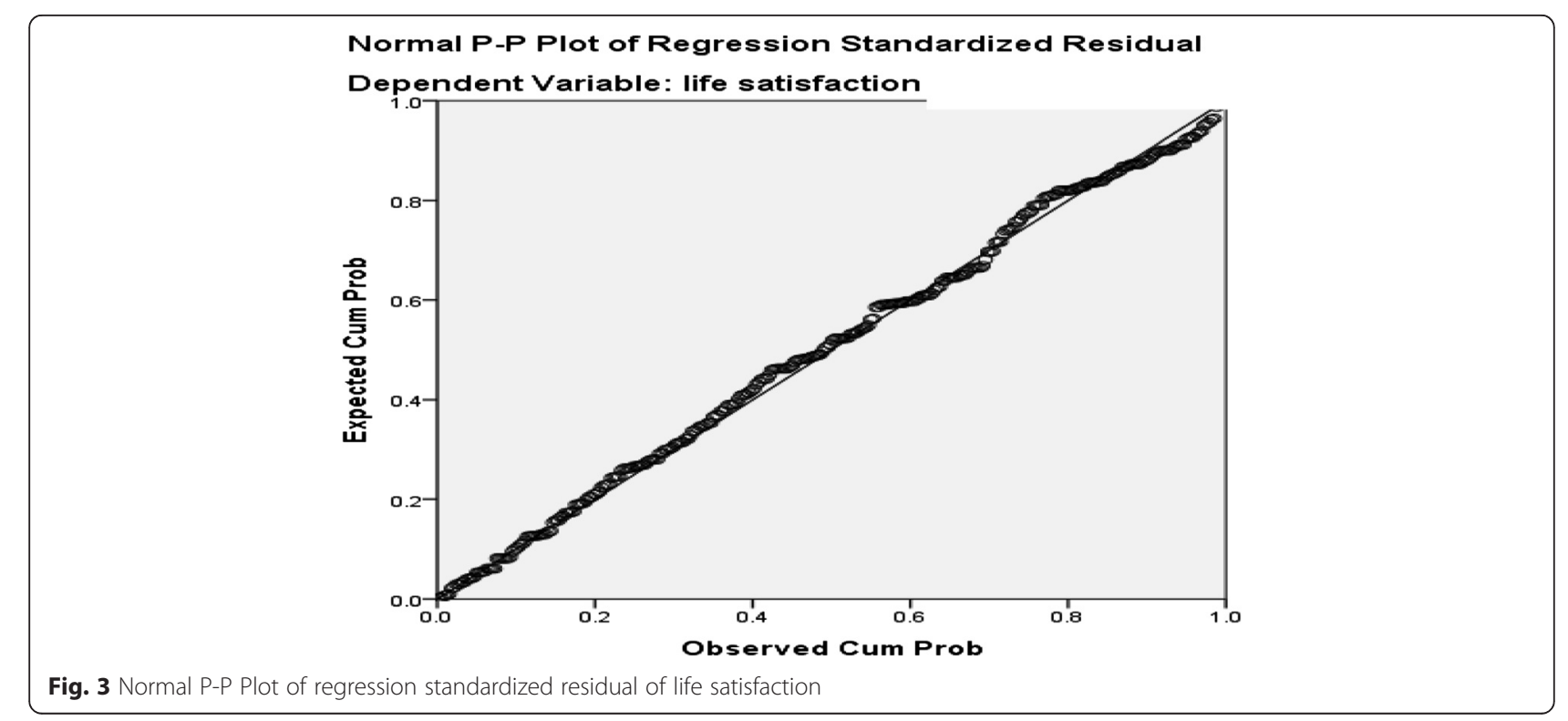




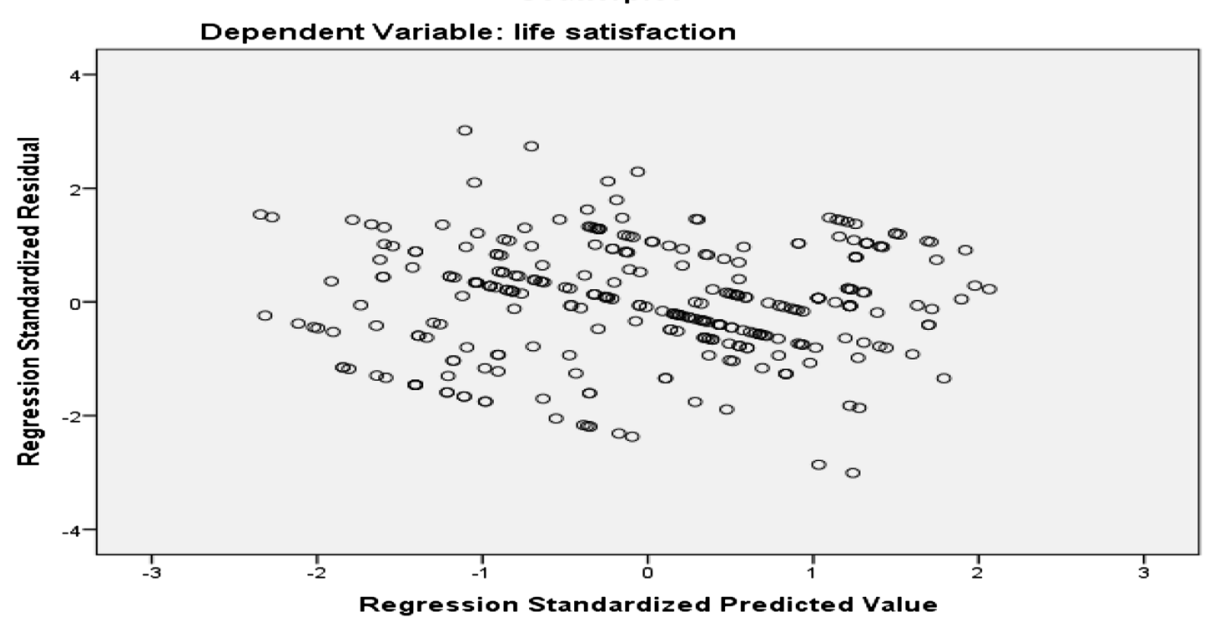

Fig. 4 Scatter plot of life satisfaction among elderly population

social support and financial status of their children. In case if the elderly people are having similar mind set as of their children, they can enjoy a healthier and happier life span with them. Moreover if they have enough financial resources to meet their basic needs and have adequate social support then they have higher LS. Living alone results into lower LS than those elderly who are living with spouse or their children $[61,62]$.

Our results conclude that most important variable which affects the level of LS of the rural elderly is cognitive health status. In this study, majority of the sampled elderly $(50 \%)$ were recorded with bad cognitive health. Elderly having low GHQ -12 score are prone to depression leading to lower LS [29]. The relationship between cognitive health status and LS is very crucial which can be assessed from the individuals' overall cognitive assessment of their living conditions and achievements, comparing them to their needs and expectations and in light of their personal and socio-cultural values [63]. The second most influential factor on LS is social support. Many studies have reported that social activities or interpersonal relationship enhances both physical and mental health. It lowers mortality rates among elderly [61, 62]. Social supports improves one's self esteem, sense of belongingness and gives a purpose to life. It also provides physiological benefits such as better immune functioning and increased cardiovascular activities. It also promotes positive health behaviour like proper diet, exercise and helps a person to stay away from risky behaviour such as smoking and consumption of alcohol [64]. However the degree of social supports varies with the disability and morbidity status of an individual [65]. The next important factor effecting LS among rural elderly was morbidity status. There was an inverse relationship between the morbidity status of a person and his LS. Good health allows the person to maintain social contacts, resulting in higher level of LS and prevalence of chronic diseases results into low level of LS. Low LS is associated with ADL and IADL which is necessary for overall QoL. Chronic conditions like diabetes, hypertension and cardiovascular diseases have adverse effect on the health and it's harmful for both cognitive and physical disabilities [66]. The other important variable for LS for rural elderly was living arrangements. In our study more than

Table 4 Model summary of LS

\begin{tabular}{|c|c|c|c|c|c|c|c|c|c|}
\hline \multicolumn{10}{|c|}{ Model Summary ${ }^{c}$} \\
\hline \multirow[t]{2}{*}{ Model } & \multirow[t]{2}{*}{ R } & \multirow{2}{*}{$\begin{array}{l}\text { R } \\
\text { Square }\end{array}$} & \multirow{2}{*}{$\begin{array}{l}\text { Adjusted } \\
\text { R Square }\end{array}$} & \multirow{2}{*}{$\begin{array}{l}\text { Std. } \\
\text { Error of } \\
\text { the } \\
\text { Estimate }\end{array}$} & \multicolumn{5}{|l|}{ Change Statistics } \\
\hline & & & & & R Square Change & F Change & df1 & $\mathrm{df2}$ & Sig. F Change \\
\hline 1 & $.552^{\mathrm{a}}$ & .304 & .266 & 3.498 & .304 & 8.014 & 16 & 293 & .000 \\
\hline 2 & $.583^{\mathrm{b}}$ & .350 & .302 & 3.513 & .086 & 15.796 & 1 & 292 & .000 \\
\hline
\end{tabular}

a*predictors: (constant) age, caste, marital status, education, wealth index, state of economic dependence, living arrangements, life style indicators, activities of daily living, cognitive healh and social adjustment

b*predictors: (constant) age, caste, marital status, education, wealth index, state of economic dependence, living arrangements, life style indicators, activities of daily living, cognitive health and social adjustment, gender

$c^{*}$ dependent variable: life satisfaction 
Table 5 Model design for regression analysis

\begin{tabular}{|c|c|c|c|c|c|}
\hline Models & Model 1 & Model 2 & Model 3 & Model 4 & Model 5 \\
\hline Variables & $\begin{array}{l}\text { Only } \\
\text { demographic } \\
\text { variables }\end{array}$ & $\begin{array}{l}\text { Only Socio- } \\
\text { economic variables }\end{array}$ & Only life style indicators & $\begin{array}{l}\text { All independent } \\
\text { covariates }\end{array}$ & All independent covariates \\
\hline & - Age & - Education & - State of economic dependence & $\begin{array}{l}\text { - ADL (activities of } \\
\text { daily living) }\end{array}$ & - Age \\
\hline & \multirow[t]{12}{*}{ - Marital status } & - Wealth Index & - Living arrangements & - Social supports & - Marital status \\
\hline & & - Caste & $\begin{array}{l}\text { - Risk behaviour (Smoking, } \\
\text { Consuming tobacco and alcohol) }\end{array}$ & & - Education \\
\hline & & & & & - Wealth quintile \\
\hline & & & & & - Caste \\
\hline & & & & & - State of economic dependence \\
\hline & & & & & - Living arrangement \\
\hline & & & & & $\begin{array}{l}\text { - Risk behaviour (Smoking, } \\
\text { Consuming tobacco and alcohol) }\end{array}$ \\
\hline & & & & & - ADL (activities of daily living) \\
\hline & & & & & - Social supports \\
\hline & & & & & - Disability \\
\hline & & & & & - Cognitive health \\
\hline & & & & & - Morbidity status \\
\hline
\end{tabular}

Table 6 Model design for multiple linear regression for LS for males

\begin{tabular}{|c|c|c|c|c|c|}
\hline Variables & Model I & Model II & Model III & Model IV & Model V \\
\hline Age of the respondents ${ }^{\mathrm{b}}$ & 0.003 & 0.005 & 0.004 & 0.015 & 0.019 \\
\hline Marital status ${ }^{\mathrm{b}}$ & 0.936 & 0.084 & 0.007 & 0.004 & -0.023 \\
\hline Education $^{a}$ & & -0.02 & -0.032 & -0.007 & -0.008 \\
\hline Wealth quintile ${ }^{a}$ & & 0.196 & 0.136 & 0.125 & 0.069 \\
\hline Castle $^{\mathrm{b}}$ & & 0.009 & -0.023 & -0.053 & 0.052 \\
\hline State of economic dependence ${ }^{b}$ & & & 0.044 & 0.044 & 0.074 \\
\hline Living arrangements $^{\mathrm{b}}$ & & & $0.165^{* *}$ & 0.161 & 0.179 \\
\hline \multicolumn{6}{|l|}{ Risk behaviours } \\
\hline a) Smoking ${ }^{\text {b }}$ & & & 0.029 & 0.061 & 0.102 \\
\hline b) Consumption of alcohol ${ }^{b}$ & & & 0.3 & 0.28 & 0.357 \\
\hline c) Consuming tobacco ${ }^{b}$ & & & 0.109 & 0.162 & 0.068 \\
\hline Activities of daily living $(A D L)^{b}$ & & & & $-0.546^{*}$ & $-0.287^{*}$ \\
\hline Social supports ${ }^{\mathrm{b}}$ & & & & $0.192^{* *}$ & $0.286^{* *}$ \\
\hline Disability ${ }^{\mathrm{b}}$ & & & & & $-0.479^{* *}$ \\
\hline Cognitive health ${ }^{b}$ & & & & & $0.327^{*}$ \\
\hline MOrbidity status ${ }^{b}$ & & & & & -0.077 \\
\hline Adjusted $R^{2}$ & 0.002 & 0.116 & 0.155 & 0.244 & 0.384 \\
\hline Change in Adjusted $\mathrm{R}^{2}$ & & 0.114 & 0.039 & 0.089 & 0.140 \\
\hline
\end{tabular}

** $\rho<0.05 ;{ }^{*} \rho<0.01$

Dependent Variable: Likert scale (1.very happy, 2.happy, 3. neither happy nor unhappy, 4. unhappy, and 5. very unhappy

The suggested figures in all cells are standardized B

${ }^{a}$ Continous variables: 5 -point Likert scale

binary variables 
Table 7 Model design for multiple linear regression for LS for females

\begin{tabular}{|c|c|c|c|c|c|}
\hline Variables & Model I & Model II & Model III & Model IV & Model V \\
\hline Age of the respondents ${ }^{\mathrm{b}}$ & 0.002 & 0.005 & 0.005 & 0.016 & 0.02 \\
\hline Marital status ${ }^{\mathrm{b}}$ & 0.905 & 0.091 & 0.067 & -0.003 & -0.031 \\
\hline Education $^{\mathrm{a}}$ & & 0.026 & -0.025 & -0.001 & -0.002 \\
\hline Wealth quintile ${ }^{a}$ & & 0.196 & 0.136 & 0.125 & 0.068 \\
\hline Castle $^{+}$ & & 0.008 & -0.02 & -0.051 & 0.054 \\
\hline State of economic dependence ${ }^{b}$ & & & 0.041 & 0.041 & 0.072 \\
\hline Living arrangements ${ }^{\mathrm{b}}$ & & & $0.164^{* *}$ & $0.16^{*}$ & 0.178 \\
\hline \multicolumn{6}{|l|}{ Risk behaviours } \\
\hline a) Smoking ${ }^{b}$ & & & 0.025 & 0.57 & 0.098 \\
\hline b) Consumption of alcohol ${ }^{b}$ & & & 0.283 & 0.264 & 0.342 \\
\hline c) Consuming tobacco ${ }^{b}$ & & & 0.109 & 0.162 & 0.17 \\
\hline Activities of daily living (ADL) $)^{b}$ & & & & $-0.548^{* *}$ & $-0.288^{*}$ \\
\hline Social supports ${ }^{b}$ & & & & $0.189^{*}$ & $0.284^{* *}$ \\
\hline Disability $^{\text {b }}$ & & & & & $-0.476^{*}$ \\
\hline Cognitive health ${ }^{\mathrm{b}}$ & & & & & $0.329^{* *}$ \\
\hline MOrbidity status ${ }^{\mathrm{b}}$ & & & & & -0.074 \\
\hline Adjusted $R^{2}$ & 0.004 & 0.119 & 0.159 & 0.246 & 0.386 \\
\hline Change in Adjusted $R^{2}$ & & 0.115 & 0.040 & 0.087 & 0.140 \\
\hline
\end{tabular}

** $\rho<0.05 ;{ }^{*} \rho<0.01$

Dependent Variable: Likert scale (1.very happy, 2.happy, 3. neither happy nor unhappy, 4. unhappy, and 5. very unhappy

The suggested figures in all cells are standardized B

${ }^{a}$ Continous variables: 5-point Likert scale

${ }^{b}$ Binary variables

half of the elderly were living with spouse and married son. Elderly living with family members showed increased LS than those living alone or with relatives. Elderly living alone are unable to meet their basic requirements in case of disability and chronic conditions. Having support from family members reduces the effect of diseases and it gives them will power and strong mental attitude to manage their day to day life. Living arrangements influences the cognitive health and level of LS. Loneliness is a biggest enemy in old age which pushes a person towards morbidity leading to disability [67-69]. Living arrangements acts as a powerful instrument in defining roles among elderly as it gives a sense of belongingness and provides social support both formal and informal [70-72]. Spouse can be an important support for both male and females as the males can looks after for finances and females take care of health issues [53].

\section{Limitations of the study}

It was a major challenge to explain to the respondents and their family members about the reason behind this study and the underlying benefit to them. Many respondents were curious to know whether they will receive any financial benefit from the government or not. This is a cross sectional study and results may change over time. This study takes into consideration only self-reported cases for any sort of morbidity and disability. No clinical examination has been performed, so the results may vary. The study is confined to few villages of Bargarh district in Odisha. It can be extended to other districts also to provide a probable solution to the problems faced by elderly that can be useful for the decision makers in future for policy implications.

\section{Conclusions}

In this study, the subjective meaning of ageing is determined on the basis of the LS model. Factors such as cognitive status, morbidity status, and social supports can be the areas of concern and special focus for the gerontologist. Interdisciplinary research with the aim of increasing LS in the elderly should be promoted. Management of health conditions and ADL, IADL functioning plays a pivotal role in increasing LS among elderly. The issue of cognitive wellbeing remained unidentified especially among the elderly population. This issue needs more attention as sound cognitive health can enhance the overall LS among the elderly. Our study brings into focus this unattended issue of cognitive health which can be looked into by the policy makers. Proper designing of the welfare programmes, policies and regulations for elderly needs a better understanding of the relationship between people's individual characteristics and their perceptions regarding 
LS. There should be well trained staff and infrastructure in the geriatric units to cater the cognitive needs of the rural elderly which is fully ignored at present in India. In the Indian context social support system is essential for ensuring psychological wellbeing among the elderly population. More stress should be laid upon the counseling among the younger generation which can encourage them to support and look after the needs of their elderly as it will enhance the level of LS. There should be more focus in building intergenerational solidarity among the two generations which will improve the social support. Disabled elderly should be given special attention by the society and more user-friendly environment should be provided to them. This study can contribute positively in the overall feeling of happiness among the elderly population which may become a basis for the formulation of policies to improve the QoL in the county like India. The implication of our findings can be adopted by the government agencies and police maker to identify the major areas of attention and to identify the most vulnerable aged people (70 above), particularly aged females/widows.

\section{Endnotes}

${ }^{1}$ Health inequity refers to the unfair distribution of health determinants, outcomes and resources within and between segments of the population, regardless of social standing (CDC, 2010).

${ }^{2}$ Territorial or administrative units from the hierarchy of census, India.

${ }^{3} \mathrm{~A}$ village is a clustered human settlement or community, larger than a hamlet but smaller than a town, where population ranges between few hundred to a few thousand.

${ }^{4}$ The caste system in India is a closed system of social stratification with its origin in pre-modern era that uses to determine the access to wealth power and privilege in India.

\section{Abbreviations \\ ADL: Activities of daily living; BPL: Below Poverty Line; COPD: Chronic Obstructive Pulmonary Disease; DV: Dependent variable; HRQOL: Health- Related Quality of Life; IADL: Instrumental activities of daily living; IV: Independent variable; LoC: Locus of control; LS: Life satisfaction; OBC: Other Backward Caste; PPS: Probability proportion to sample size; QoL: Quality of life; SC: Scheduled Caste; SEM: Structural Equation Modeling; ST: Scheduled Tribe; SWB: Subjective wellbeing.}

\section{Competing interest}

The authors declare that they have no competing interests.

\section{Authors' contribution}

PB planned the study analyzed the data and wrote the article, with contributions from RD and JP. JP has supervised the data analysis and helped her to plan the study; RD has contributed in the revision and finalization of the paper. All authors read and approved the final manuscript.

\section{Acknowledgements}

The authors are grateful to the Department of Humanities and Social Sciences, National Institute of Technology, Rourkela for their support and encouragement, which has helped in improving this paper. We received no funding support to undertake this study.
Received: 26 May 2015 Accepted: 15 December 2015

Published online: 21 December 2015

\section{References}

1. Stalbrand IS, Svensson T, Elmstahal S, Horstmann V, Hagbergm B, Dehlin O, et al. Subjective health and illness, coping and life satisfaction in 80-year-old Swedish population-implications for mortality. Int J Behav Med. 2007;14:173-80.

2. Jauhiainen JS. Will the retiring baby boomers return to rural periphery? Rural Stud. 2009;25(1):25-34.

3. Diener E, Emmons RA, Larsen RJ, Griffin S. The satisfaction with life scale. J Pers Assess. 1985:49(1):71-5.

4. Freund AM, Riediger MA. Successful aging. In: Lerner RM, M. A. Easterbrook's \& J. Mistry, editors. Handbook of psychology. 6th ed. New York: Wiley; 2003. p. 601-28.

5. Chou KL, Chi I. Successful aging among the young-old, old-old, and oldest-old Chinese. Int J Aging Hum Dev. 2002;54(1):1-14.

6. Shin DC, Johnson DM. Avowed happiness as an overall assessment of the quality of life. Soc Indic Res. 1978;5:475-92.

7. Lee SG, Jeon SY. The relations of socioeconomic status to health status, health behaviours in the elderly. J Prev Med Public Health. 2005:38(2):154-62.

8. Efklides A, Maria K, Grace C. Subjective quality of life in old age in Greece, the effect of demographic factors, emotional state, and adaptation to aging. Eur Psychol. 2003;8:178-91.

9. Hang KC, Hong IS. Assets and Life Satisfaction Patterns among Korean Older Adults: Latent Class Analysis. Asset and Life Satisfaction Patterns. 2010;100:225-40.

10. Ferring FD, Balducci $C$, Burholt V, Wenger C, Thissen F, Weber G, et al. Life satisfaction of older people in six European countries: findings from the European study on adult well-being. Eur J Ageing. 2004;1:15-25.

11. Subasi F, Hayran O. Evaluation of life satisfaction index of the elderly people living in nursing homes. Arch Gerontol Geriat. 2005:41:23-9.

12. Delhey J. Life Satisfaction in an Enlarged Europe. Luxembourg: Office for Official Publications of the European Communities; 2004.

13. Mroczek DK, Spiro A. Change in life satisfaction during adulthood: findings from the veteran's affairs normative aging study. J Pers Soc Psychol. 2005; 88:189-202.

14. Bennett KM. Psychological wellbeing in later life: The longitudinal effects of marriage, widowhood and marital status change. Int I Geriatr Psychiatry. 2005;20(3):280-4.

15. Schoenborn CA. Marital status and health, United States 1999-2002. US Department of Health and Human Services, Centers for Disease Control and Prevention, National Center for Health Statistics, 2004.

16. Suh S, Choi H, Lee C, Cha M, Jo I. Association between knowledge and attitude about aging and life satisfaction among older Koreans. Asian Nurs Res. 2012;6(3):96-101.

17. Ra J, An S, Rhee KJ. The Relationship between Psychosocial Effects and Life Satisfaction of the Korean Elderly: Moderating and Mediating Effects of Leisure Activity. JAH. 2013;2(11):21-35.

18. Fernandez-Ballesteros R, Zamarron MD, Ruiz MA. The contribution of sociodemographic and psychosocial factors to life satisfaction. Aging and Society. 2001;21:25e43.

19. Şener A, Oztop H, Dogan N, Guvev S. Family, close relatives, friends: life satisfaction among older people. Educ Gerontol. 2008:34:890-906.

20. Parker PD, Martin AJ, Marsh HW. Factors predicting life satisfaction: A process model of personality, multidimensional self-concept, and life satisfaction. Aust J Guid Couns. 2008:18:15-29.

21. Nakahara J. Effects of Social Activities outside the Home on Life Satisfaction among Elderly People Living Alone. IJPS. 2013;5(1):112-20.

22. Markides K, Martin S. A causal model of life satisfaction among the elderly. J Gerontol. 1979:34:86-93.

23. Asberg $\mathrm{KH}$, Sonn $\mathrm{U}$. The cumulative structure of personal instrumental $\mathrm{ADL}$ A study of elderly people in a health service district. Scand I Rehabil Med. 1988;21:171-7.

24. Hsu HC, Jones BL. Multiple Trajectories of Successful Aging of Older and Younger Cohorts. The Gerontologist. 2012. doi: 10.1093/geront/gns005.

25. Deaton A. Income, aging, health and wellbeing around the world: Evidence from the Gallup World Poll. No. w13317. National Bureau of Economic Research, 2007.

26. Keyes CLM, Shmotkin D, Ryff C. Optimizing well-being: the empirical encounter of two traditions. J Pers Soc Psychol. 2002;82:1007-22.

27. Berg Al, Hoffman L, Hassing LB, McClearn GE, Johansson B. What matters, and what matters most, for change in life satisfaction in the oldest-old? A 
study over 6 years among individuals 80+. Aging and Mental Health. 2009; 13:191-201.

28. Antonucci TC, Sherman AM, Akiyama H. Social supports, support, and integration. In: Birren JE, editor. Encyclopedia of Gerontology. 2nd ed. San Diego. CA: Pergamon Press; 1996. p. 408-16.

29. Villar F, Sole C, Osuna MJ, Triado C. La medidadelbienestaren personas mayores: adaptación de la EscalaRyff. Rev Psicología Gen. 2005;58:347-64.

30. Melendez JC, Toma's JM, Oliver A, Navarro E. Psychological and physical dimensions explaining life satisfaction among the elderly: A structural model examination. Arch Gerontol Geriatr. 2009:48:291-5.

31. Won M, Choi Y. Are Koreans Prepared for the Rapid Increase of the SingleHousehold Elderly? Life Satisfaction and Depression of the Single-Household Elderly in Korea. The Scientific World Journal, doi:10: 2013; 1155/2013/972194 DOl: 10.1155\%2F2013\%2F972194\#pmc_ext.

32. Yeh SC, Shih CT, Chuang CH, Tsay SF. The Relationship between Socia Supports and Life Satisfaction for Elderly in Kaohsiung. Manag Rev. 2004; 12(2):399-427.

33. Krause N. Common facets of religion, unique facets of religion, and life satisfaction among older African Americans. J Gerontol B Psychol Sci Soc Sci. 2004:59:109-17.

34. Deng J, Hu J, Wu W, Dong B, Wu H. Subjective well-being, social support, and age-related functioning among the very old in China. Int J Geriatr Psychiatry. 2010;25:697-703.

35. Ho KH, Matsubayashi K, Wada T, Kimura M, Yano S, Otsuka K, et al. What determines the life satisfaction of the elderly? Comparative study of residential care home and community in Japan. Geriatr Gerontol Int. 2003;3: 79-85.

36. Pinquart M, Sorensen S. Influence of socioeconomic status, social support, and competence on subjective well-being in later life: a meta-analysis. Psychol Aging. 2001;15:187-224.

37. Landau R, Litwin H. Subjective well-being among the old-old: the role of health, personality and social support. Int J Aging Hum Dev. 2012;52:65-280.

38. Boonphadung S. Factors Effecting Life Satisfaction of the Elderly in Bangkok. JCC. 2013;10:894-903.

39. Chen J, Murayama S, Kamibeppu K. Factors related to well-being among the elderly in urban China focusing on multiple roles. BioScience Trends. 2010;4:61-71.

40. Jung M, Muntaner C, Choi M. Factors Related to Perceived Life Satisfaction among the Elderly in South Korea. J Prev Med Public Health. 2010;43(4):292-300.

41. Mollaoglu M, Tuncay FO, Fertelli TK. Mobility disability and life satisfaction in elderly people. Arch Gerontol Geriatr. 2010;51(3):e115-9. doi:10.1016/j. archger.2010.02.013. Epub 2010 Mar 24

42. Marum G, Clench-Aas J, Nes RB, Raanaas RK. The relationship between negative life events, psychological distress and life satisfaction: a population-based study. Qual Life Res. 2014;2:601-11. doi:10.1007/s11136013-0512-8. Epub 2013 Sep 13.

43. Helvik AS, Engedal K, Krokstad S, Selbæk G. A comparison of life satisfaction in elderly medical inpatients and the elderly in a population-based study: Nord-Trøndelag Health Study 3. Scand J Public Health. 2011;39(4):337-44.

44. Maheswaran T, Ranjit L. A study on Life Satisfaction among Elderly People. Res J Sociology. 2013;1:1-8

45. Balachandran M, Raakhee AS, Sam Sananda Raj H. Life Satisfaction and Alienation of Elderly Males and Females. J Indian Academy Appl Psychol. 2007;33(2):157-60.

46. Marpady P, Jyothi PS, Singhe MS. Social support network and life satisfaction among elders in Mangalore Taluk: An implication for social work intervention. Elixir Soc Sci. 2012;48:9457-60.

47. Census of India. Census of India Single year age distribution office of the registrar general of India, New Delhi. 2011.

48. Coke MM, Twaite JA. The Black Elderly: Satisfaction and Quality of Later Life. NY: The Haworth Press; 1995.

49. Neugarten BL, Havighurst RJ, Tobin SS. The measurement of life satisfaction. J Gerontol. 1961;16:134-43

50. Noelker LS, Browdie R, Sidney Katz MD. A new paradigm for chronic illness and long-term care. Gerontologist. 2013;8(6):1-8.

51. Wise EA, Price DD, Myers CD, Heft MW, Robinson ME. Gender role expectations of pain: relationship to experimental pain perception. Pain. 2002;96(3):335-42.

52. Vera-Sanso P. They don't need it, and I can't give it': Filial support in South India. Aging without Children: European and Asian Perspectives on Elderly Access to Support Networks. Oxford: Berghahn Books; 2005. p. 77-105.
53. Oshio T. Gender differences in the associations of life satisfaction with family and social relations among the Japanese elderly. J Cross Cult Gerontol. 2012;27(3):259-74.

54. Humpert S. Gender differences in life satisfaction and social participation. Intl J Econ Sci Appl Res. 2013;3:123-42.

55. Sokolovsky J. Ethnicity, culture and aging: Do differences really make a difference? J Appl Gerontol. 1985;4(1):6-17.

56. Tabachnick BG, Fidell LS. Using Multivariate Statistics. 4th ed. Allyn \& Bacon: Needham Heights, MA; 2001.

57. Nguyen AW, Taylor RJ, Peterson T, Chatters LM. Health, Disability, Psychological Well-Being, and Depressive Symptoms among Older African American Women. Women, Gender, and Families of Color. 2013;1(2):105-23.

58. Sato S, Demura S, Kobayashi H, Nagasawa Y. The relationship and its change with aging between ADL and daily life satisfaction characteristics in independent Japanese elderly living at home. J Physiol Anthropol Appl Hum Sci. 2002;21(4):195-204.

59. Chappell NL, Cooke HA. Age related disabilities-aging and quality of life. International Encyclopedia of Rehabilitation. 2010:1-3.

60. Chen C. Ageing and life satisfaction. Soc Indic Res. 2000;54(1):57-79.

61. Kooshiar H, Yahaya N, Hamid TA, Abu Samah A, SedaghatJou V. Living Arrangement and Life Satisfaction in Older Malaysians: The Mediating Role of Social Support Function. PLoS One. 2012;7(8):e43125. doi:10.1371/journal. pone.0043125.

62. Diener E, Ryan K. Subjective well-being: A general overview. South African J Psychol. 2009;39:391-406.

63. Everard KM, Lach HW, Fisher EB, Baum MC. Relationship of activity and social support to the functional health of older adults. J Gerontol: Soc Sci. 2000;55B:S208-12.

64. Raj D, Swain PK, Pedgaonkar SP. A study on quality of life satisfaction \& physical health of elderly people in Varanasi: An urban area of Uttar Pradesh, India. Int J Med Sci Publ Health. 2014;3(5):616-20.

65. Berkman L, Glass T, Brissette I, Seeman T. From social integration to health: Durkheim in the new millennium. Soc Sci Med. 2000:51:843-57.

66. Pinto JM, Neri AL. Factors associated with low life life satisfaction in communitydwelling elderly: FIBRA Study. Cad Saude Publica. 2013:29(12):2447-58.

67. Leon JB, Mitchell AJ, Vega S, Bermejo-Pareja F. A population-based study of cognitive function in older people with subjective memory complaints. J Alzheimers Dis. 2010;22:159-70.

68. Kim CS. Social theories and discourses on population aging. J Korea Gerontol Soc. 2007;27(3):667-90.

69. Zhang W, Liu G. Childlessness, psychological well-being, and life satisfaction among the elderly in China. J Cross Cult Gerontol. 2007;22(2):185-203.

70. Panigrahi AK. Living Arrangement Preferences of the Elderly in Orissa, India. Institute for Social and Economic Change. 2010

71. Gupta R, Pillai VK. Elder caregiving in South-Asian families in the United States and India. Social Work \& Society. 2012;10(2).

72. Jadhav A, Sathyanarayana KM, Kuma S, James KS. Living Arrangements of the Elderly in India: Who lives alone and what are the patterns of familial support? Busan, Korea: IUSSP; 2013.

\section{Submit your next manuscript to BioMed Central and we will help you at every step:}

- We accept pre-submission inquiries

- Our selector tool helps you to find the most relevant journal

- We provide round the clock customer support

- Convenient online submission

- Thorough peer review

- Inclusion in PubMed and all major indexing services

- Maximum visibility for your research

Submit your manuscript at www.biomedcentral.com/submit
Biomed Central 